Research Article

\title{
Determinants of Wheat Commercialization among Smallholder Farmers in Debre Elias Woreda, Ethiopia
}

\author{
Birara Endalew (D), ${ }^{1}$ Mezegebu Aynalem, ${ }^{2}$ Fenta Assefa, ${ }^{3}$ and Zemen Ayalew ${ }^{1}$ \\ ${ }^{1}$ Department of Agricultural Economics, Bahir Dar University College of Agriculture and Environmental Sciences, \\ Bahir Dar, Ethiopia \\ ${ }^{2}$ Department of Agribusiness and Value Chain Management, Debere Markos University, Debre Markos, Ethiopia \\ ${ }^{3}$ Department of Plant Science, Raya University College of Agriculture and Natural Resources, Maichew, Ethiopia \\ Correspondence should be addressed to Birara Endalew; birara.endalew@gmail.com
}

Received 12 December 2019; Revised 12 December 2019; Accepted 17 June 2020; Published 6 August 2020

Academic Editor: Mumtaz Cheema

Copyright (c) 2020 Birara Endalew et al. This is an open access article distributed under the Creative Commons Attribution License, which permits unrestricted use, distribution, and reproduction in any medium, provided the original work is properly cited.

\begin{abstract}
Even though wheat commercialization has got great emphasis, smallholder farmers face challenges to participate in the wheat market. As a result, understanding the intensity of smallholder farmers' wheat commercialization and factors affecting wheat commercialization has vital importance to tackle the problem. Consequently, this study was undertaken in northwestern Ethiopia to measure smallholder farmers' wheat commercialization and analyze factors that hamper wheat commercialization in the study area. For this purpose, a systematic sampling technique has been employed to select a total of 154 smallholder wheat producer household heads. A semistructured questionnaire has been used as a principal primary data collection method. Similarly, the output commercialization index and the beta regression model have been employed for data analysis. The result of the study showed that $23.4 \%, 51.9 \%$, and $24.7 \%$ of smallholder farmers were subsistence, semicommercialized, and commercialized, respectively. The result indicated that the majority of smallholder farmers are semicommercial wheat producers. Moreover, the beta regression result indicated that educational status, number of oxen, land size allocated to wheat production, farming experience in wheat production, extension service, and market distance are major factors for smallholder farmer's wheat commercialization. Therefore, an attempt to increase smallholder farmers' wheat commercialization should give special priority for significant explanatory variables.
\end{abstract}

\section{Introduction}

Commercialization in agriculture refers to the progressive shift from household production for consumption to market-oriented production [1]. Agricultural commercialization results in welfare gains for farmers through comparative advantage and increased total factor productivity growth [2] because the commercialization of smallholder agriculture leads to productivity growth, income growth, employment growth, and poverty reduction [3]. Similar studies revealed that agricultural commercialization also improves food supply in urban areas, with broader growth and welfare effects [4]. The study by Tipraqsa and Schreinemachers [5] pointed out that commercialized farmers have a better living standard than subsistence farmers. This is because commercialized smallholder farmers have used more advanced production systems which are based on a comparative advantage. Consequently, higher production is achieved through economies of scale, regular interaction, exposure to new ideas, greater learning by doing, and better incentives in the form of high income, which of course have welfare gains for smallholder farmers [6].

In Ethiopia, $95 \%$ of the total area is cultivated by smallholder farmers and $90 \%$ of the total agricultural products are obtained from smallholder farmers $[7,8]$. In the long run, this subsistence agricultural production may not be a viable production system to ensure food security [9]. Therefore, commercializing smallholder agriculture is seen as a means to bring the welfare benefits of market-based exchange economies and is central to an inclusive 
development process [10]. This implies that commercializing smallholder agriculture is an indispensable pathway towards economic growth and development for most developing countries relying on the agricultural sector as a means of livelihood [11]. Especially, the development of the Ethiopian economy heavily depends on the rate that a subsistence production system is transformed into a market-orientated production system [12]. This entails that the poverty-reduction strategy seeks to achieve growth through the commercialization of smallholder agriculture [13]. Consequently, promoting the commercialization of agricultural production is a cornerstone of the rural development and poverty-reduction strategies of Ethiopia [14, 15].

The Ethiopian agriculture sector is composed of the crop, livestock, forestry, and fishing subsectors of which the crop subsector takes the lion's share of the agriculture sectors, comprising $65.3 \%$, followed by livestock production (25.3\%) [16]. As discussed by CSA [17], the crop production subsector is showing improvement in terms of productivity and the extent and use of modern farm inputs and modern farming system practices though the production comes from smallholder farmers. In Ethiopia, grain crop production is the most widely spread crop production activity both in terms of the extent of cropped land area and volume of production [18]. Cereal crops that are classified within the grain crops category are also produced in greater volume compared to the other crops by commercial farms because they are the principal staple crops and export commodities $[18,19]$. But, the majority of the farmers in Ethiopia are smallholder farmers, producing mostly for own consumption and generating only a small marketed surplus [20]. Especially, five major bowls of cereal (teff, maize, sorghum, barley, and wheat) are the core of Ethiopia's agriculture, accounting for about $75 \%$ of the total area cultivated [7]. Among cereal crops, wheat ranks third in total grain production and second in yield next to maize [21]. In Ethiopia, wheat is one of the largest produced cereal crops in terms of the area coverage (1.6 million hectares), the volume produced (3.9 million tons), and the number of farmers engaged in wheat production (4.7 million farmers) with an average productivity of 2.4 tons per hectare [22, 23].

Additionally, wheat is an important food crop in the world, with an estimated 36 million tons of annual global production [24]. The largest wheat-producing countries are Turkey, Canada, Italy, India, France, Greece, Morocco, Pakistan, Portugal, Kazakhstan, Russia, Spain, Australia, and sub-Saharan African countries [25-27]. In sub-Saharan Africa, Ethiopia is the largest producer of wheat, with approximately 0.6 million ha [28]. In Ethiopia, wheat has been selected as one of the target crops in the strategic goal of attaining national food self-sufficiency [29]. Additionally, wheat is also an important market-oriented commodity and a major source of income for many smallholder farmers in Ethiopia [30]. Even though it has a huge potential, only 20\% of the total wheat production is sold, while $80 \%$ of its total production is used for human consumption, seed, in-kind payments for labor, and animal feed [1]. The smallholders in the country are improving their way of life through growing and selling wheat produce so that the government promotes them to produce more for alleviating poverty [31]. But, smallholder farmers are producing wheat mostly for subsistence and not for commercial purposes. Due to this reason, they earn little economic benefit from their wheat produce though the commercial transformation of this subsistence production is an essential corridor to achieve food security at the national and household level [32]. Therefore, the commercialization of wheat, which is the most important food and cash crop in the world, has great potential to improve the livelihoods of smallholder farmers [24]. Additionally, wheat commercialization enhances the links between the input and output sides of agricultural markets which leads to increased production and productivity besides the market participation of smallholder farmers. Even though wheat commercialization has got a great emphasis, smallholder farmers face challenges to participate in the wheat market. As a result, understanding the intensity of smallholder farmers' wheat commercialization and its contributing factors has significant policy implications to tackle the problem [1].

For example, Mamo et al. [33] measured the wheat commercialization index and analyzed factors affecting wheat commercialization in Ethiopia using the output commercialization index and the Tobit model, respectively. In the same way, Falola et al. [34] examined the determinants of wheat commercialization in Nigeria using the Tobit model. On the other hand, Gari [35] analyzed determinants of smallholders' wheat commercialization in Ethiopia using multiple linear regression models, whereas Hailua et al. [36] examined the determinants of crop commercialization in the Tigray region, Ethiopia, using the Tobit model. But the findings vary within and across countries due to heterogeneity of factors faced by smallholder farmers [37]. Additionally, Tobit and multiple linear regression models are not appropriate to analyze commercialization index scores restricted to the interval $[0,1]$ because the fitted value of the dependent variable lies outside the unit interval (lower and upper bounds) [38-40]. In addition to methodological gaps of previous studies, the level of wheat commercialization and factors hindering wheat commercialization in Debre Elias Woreda were not studied. Therefore, this study was undertaken to figure out location-based analysis of smallholder farmers' wheat commercialization in Debre Elias Woreda, Ethiopia. This study specifically aims to measure smallholder farmers' wheat commercialization level using the output commercialization index and analyze factors that hinder wheat commercialization using a beta regression model. Therefore, the main research question of the study is what are the main determinants of smallholder farmers' wheat commercialization in Debre Elias, Northwestern Ethiopia?

\section{Materials and Methods}

2.1. Description of the Study Area. This study was conducted in Debre Elias Woreda of the Amhara region, which is located around $340 \mathrm{~km}$ northwest of Addis Ababa, Ethiopia. In the study area, smallholder farmers are engaged in livestock rearing activities and crop production. In Debre Elias Woreda, rain-fed agriculture is the dominant economic 
activity which serves as the livelihood base of smallholder farmers. Smallholder farmers in Debre Elias Woreda produce both cash and food crops simultaneously such as maize, teff, and wheat. Wheat is one of the most important cereal crops in Ethiopia widely cultivated in a wide range of altitudes from 1500 to 3000 meters above sea level. The altitude of the study area ranges from 800 to 2200 meters above sea level (Figure 1).

The most suitable agroecological zones of wheat fall between 1900 and 2700 meters above sea level [41]. Not all the altitudes of Debre Elias Woreda fall in the potential agroecological zones (1500 to 3000 meters above sea level). As a result, altitude plays an important role in the distribution of wheat production through its influence on rainfall $(1150 \mathrm{~mm})$, temperature $\left(18-27^{\circ} \mathrm{C}\right)$, and disease incidence. The Woyina Dega (midhighlands) agroecological condition of the study area accounts for $98 \%$, and the rest $2 \%$ accounts kola (low lands) [42]. Debre Elias Woreda was selected as a study area based on the following reasons: the wheat potential of the Woreda; to fill information gaps of previous studies and identify location-based empirical evidence about the level and determinants of smallholder farmers' wheat commercialization.

2.2. Methods of Data Collection. The purpose of this study is to analyze factors affecting smallholder farmers' wheat commercialization in Debre Elias Woreda. So, smallholder wheat producer farmers in Debre Elias Woreda are the target population of this study. So, respondents were drawn from the target population. As a result, a multistage random sampling technique was applied to select representative samples to address the objective of this study (Figure 2). In the first stage, four kebeles, namely, Guay, Gofchema, Genet, and Dejeba, were selected randomly among sixteen wheat-producing kebeles in consultation with the agriculture and rural development office of the Debre Elias Woreda. In the second stage, a total of 154 wheat producer households were drawn to represent the target population. In the third stage, sample smallholder farm households were allocated to sample kebeles using probability proportional to sample size (Table 1). Finally, sample smallholder farmers were selected using a systematic sampling technique based on lists of smallholder farmers obtained from the respective agriculture office of sample kebeles.

Face-to-face interview was employed to collect firsthand information to accomplish this study. Quantitative data were collected employing a semistructured survey questionnaire. To develop a draft survey questionnaire, checklists were prepared to conduct key informant interviews and focus group discussions. A total of five focus group discussions and 10 key informant interviews were made. Then, the draft questionnaire was prepared. Moreover, a pretest survey was conducted to test data collection instruments, assess the clarity of the questions for respondents, estimate the time required to finalize the interview, and revise the questionnaire accordingly. For this purpose, 20 households were randomly selected for a pretest survey before the actual survey. Then, the survey questionnaire was tailored to the local conditions. Finally, well-trained enumerators who have good experience in the household survey were employed to gather the data required for this study.

\subsection{Methods of Data Analysis}

2.3.1. Measurement of Wheat Commercialization. Crop commercialization refers to a shift from subsistence production to market-oriented production [9]. Consequently, crop commercialization indicates the degree of participation of smallholder farmers in the output market as a seller [37]. As a result, measurement of smallholder farmers' wheat commercialization tells us to what extent a given smallholder farmer is commercialized. For this purpose, the wheat commercialization index at the household level was calculated using the output commercialization formula $[11,33$, 43, 44]:

$$
\text { wheat commercialization index }=\frac{\text { value of wheat sales in markets }}{\text { value of total wheat produced }} \text {. }
$$

2.3.2. Statistical Analysis. The data were edited, coded, entered, and cleaned to make them ready for analysis. Following this, descriptive statistics and inferential statistics were used to analyze the collected data using statistical software (STATA 14 version). Descriptive statistics such as percentage, frequency, minimum, maximum, mean, and standard deviation were utilized for this study. Additionally, a chi-square test was employed to statistically measure the association between categorical variables and level of wheat commercialization, whereas the $F$-test was used to measure the mean difference between continuous variables about the level of wheat commercialization.

2.3.3. Econometric Model. Practitioners have frequently used multiple linear regression and Tobit models to analyze crop commercialization index scores which range from zero to one as a function of individual characteristics $[33,36,37,45-47]$. For example, multiple linear regression assumes that error terms are homoscedastic and normally distributed though this assumption may not hold for bounded variables [48, 49]. Similarly, the Tobit model is not the right model for the wheat commercialization index score since commercialization is measured on a scale where index scores cannot exceed the fully commercialization level [40]. Therefore, these models are not appropriate for situations where the response is restricted to the interval $[0,1]$ because the fitted value of the dependent variable lies outside the unit interval (lower and upper bounds) [38-40].

As a result, fractional outcome regression models (fractional response models and beta regression) are applicable if the dependent variable is explained in the form of fractions, proportions, rates, probabilities, and indices 


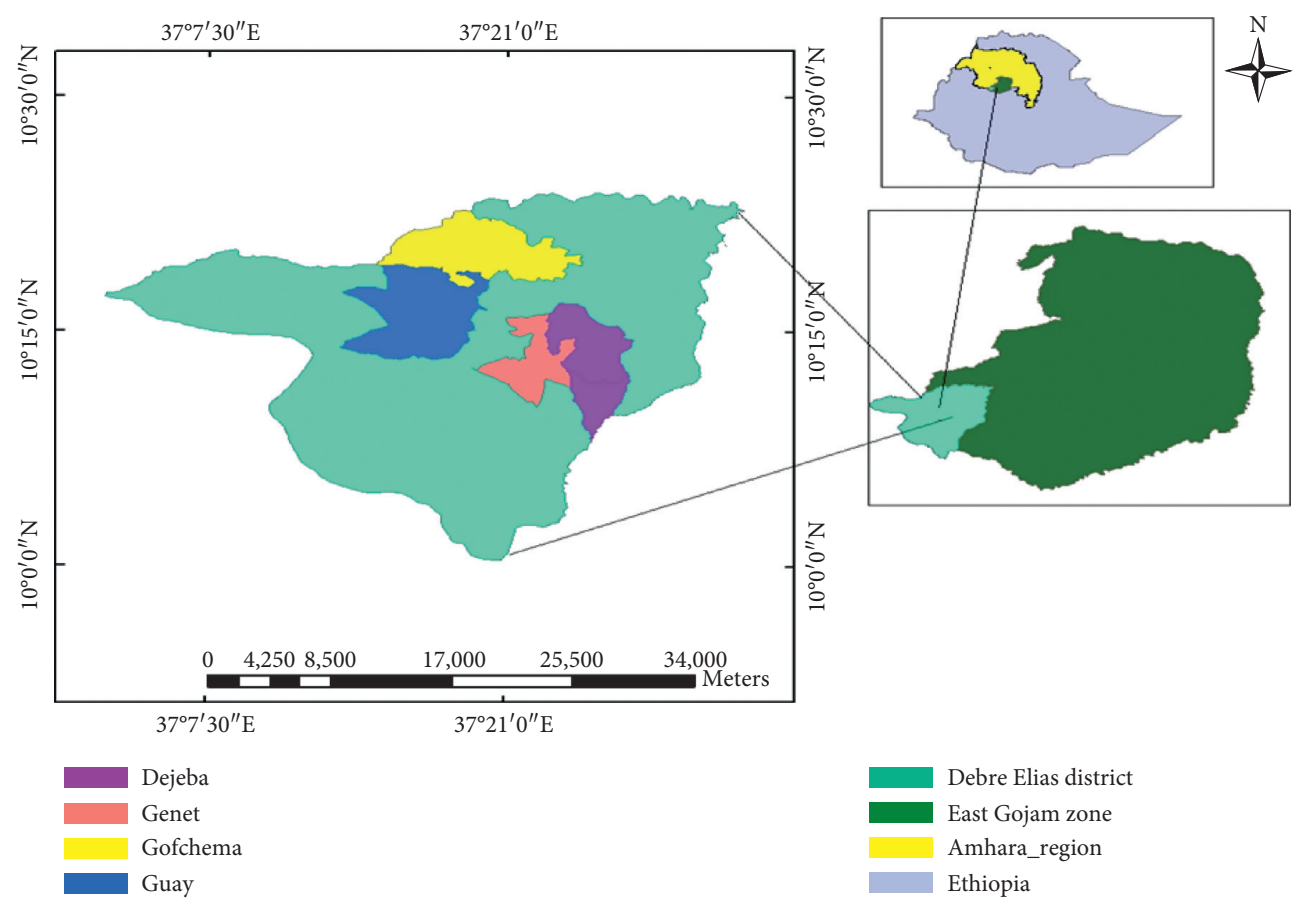

Figure 1: Map of Debre Elias Woreda.

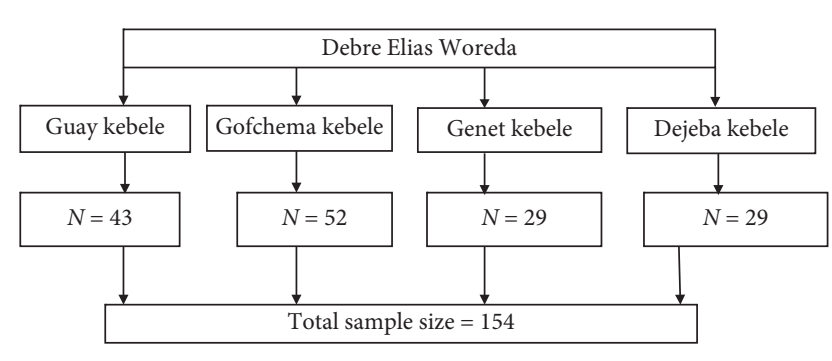

FIgURE 2: Sample selection procedure.

$[39,50]$. Fractional response models and the beta regression model capture nonlinear relationships between the fractional outcome variable and exogenous variables. Additionally, the models are used to avoid model misspecification and dubious statistical validity. For instance, fractional response models are appropriate when the outcome variable includes zero, values between zero and one, and one itself unlike the beta regression model, i.e., $0<y<1$ [50-52]. Wheat commercialization index score which ranges from 0.1 to 0.95 is the outcome variable for this study. Although the beta regression model has been employed in a different discipline to address these problems [48, 49, 53-55], it has rarely been used in the context of crop commercialization index scores. Consequently, this study applied the beta regression model to analyze the relationship between the wheat commercialization index score and exogenous variables. The outcome variable follows a beta distribution with density function given below $[38,48,50,55,56]$ :

$$
f(y ; \mu, \Phi)=\frac{\Gamma \Phi}{\Gamma(\mu \Phi) \Gamma((1-\mu) \Phi)} y^{\mu \Phi-1}(1-y)^{(1-\mu) \Phi-1}, \quad 0<y<1,
$$

where $\mu$ denotes the expected value of $Y$, i.e., $E(Y)=\mu$.

The parameter $\Phi$ fulfills the definition of a precision parameter because the greater the value of $\Phi$, the smaller the variance of the dependent variable. More specifically,

$$
\operatorname{Var}(Y)=\frac{V(\mu)}{1+\Phi}, \quad \text { where } V(\mu)=\mu(1-\mu)
$$

In the classical beta regression model, only the mean parameter $\mu$ of the beta distribution is expressed as a function of covariates, whereas the precision parameter $\Phi$ is treated as a nuisance and $E\left(y_{i} \mid X_{i}\right)=\mu_{i}[48]$ :

$$
\mu_{i}=\frac{1}{1+\exp \left(-\eta_{i}\right)}=\frac{1}{1+\exp (-x / \beta)}=g\left(x_{i}^{\prime} \beta\right), \quad \forall i,
$$

where $g(\cdot)$ is a known function with $0<g(\cdot)<1$, and the model is respecified as follows using the logit link specification $[39,54,56]$ :

$$
g\left(\mu_{i}\right)=\ln \left(\frac{\mu_{i}}{1-\mu_{i}}\right)=x_{i}^{\prime} \beta \Longrightarrow \ln \left(\frac{\mu_{i}}{1-\mu_{i}}\right)=\beta_{0}+\sum_{i=1}^{n} \beta_{i} X_{i},
$$

where $X_{i}$ denotes the vector of covariates, $\beta_{0}$ is the slope of the constant term, and $\beta_{i}$ refers to the vector of regression coefficients.

2.4. Conceptual Framework. Agricultural commercialization can be achieved when a portion of the agricultural produce from the farmers is marketed [57]. Commercialization is not only the selling of the output, but it also includes product choice and input use decisions that are based on the profit maximization principle [11]. It can occur on both sides, either on the output side with the increased output being 
Table 1: Sample size and distribution by sample kebeles.

\begin{tabular}{lccc}
\hline Kebele name & Total number of households & Share (\%) & Sample households \\
\hline Guay & 1359 & 28.2 & 43 \\
Gofchema & 1636 & 34.0 & 52 \\
Genet & 917 & 19.0 & 29 \\
Dejeba & 902 & 18.7 & 29 \\
Total & 4814 & 100 & 154 \\
\hline
\end{tabular}

marketed or the input side with the increased use of inputs [58]. But, smallholder farmers may not be able to access input and output markets due to liquidity problems, higher transaction costs, malfunctioning markets, and different socioeconomic factors [59]. As discussed by Govereh et al. [43], the smallholder farmers' participation in the output market is directly linked with the degree of commercialization.

Generally, several factors affect the commercialization of agriculture [6]. For example, Dube and Guveya [20] examined the determinants of agricultural commercialization among smallholder farmers in Manicaland and Masvingo provinces of Zimbabwe using the Tobit model. Their findings indicated that household size, availability of draft power, livestock ownership, access to irrigation, agricultural training, and household income affect agricultural commercialization positively and significantly. Likewise, Kabiti et al. [37] studied determinants of agricultural commercialization among smallholder farmers in Zimbabwe using the Tobit model. The model result reported that agricultural commercialization is determined by household size, irrigation availability, the farming experience of the household head, and nonfarm income.

On the other hand, Musah et al. [44] analyzed determinants of smallholder farmers' maize commercialization in the Upper West region of Ghana using the Tobit model. Their result mentioned that the age of the household head, gender, household size, annual household income, access to market information, and off-farm income are major and significant variables to explain maize commercialization. Likewise, Kimei et al. [60] also investigated factors influencing bean commercialization in Rwanda using the doublehurdle model. The model results show that the age of the household head, market information, number of crops a household cultivates, and market distance influenced the level of bean commercialization. Correspondingly, the study by Falola et al. [34] revealed that farm size, credit access, use of improved varieties, age of household head, household size, and nonfarm income significantly influence household commercialization of wheat production. Moreover, Bekele and Alemu [61] studied factors affecting the commercialization of smallholder farmers in the moisture-stress haricot bean-based farming systems of central Ethiopia. Their result indicated that household size, land size, age, livestock holding, and dependency ratio are the key determinants of crop commercialization. Similarly, the result by Mamo et al. [33] indicated that the educational level of household head, livestock ownership, and credit access affect wheat commercialization positively and significantly, while the distance to the market and household size affect the commercialization of farmers negatively.
According to Pender and Alemu [62] and Rabbi et al. [6], it is explained that the abovementioned factors influence commercialization by changing the conditions of demand and supply for commodity, input-output prices, transaction costs, and risk that farmers, traders, and others in the agricultural production and marketing system have to cope with. Accordingly, explanatory variables were hypothesized on wheat commercialization based on the information extracted from the theoretical literature review of previous works (Table 2).

\section{Results}

3.1. Level of Wheat Commercialization. According to Goitom [30], Mamo et al. [33], Musah et al. [44], and Pingali [9], sample smallholder farmers were categorized into three levels based on the wheat commercialization index score: subsistence $((0,0.25])$, semicommercialized $((0.25,0.5])$, and commercialized $(>0.5)$. The result revealed that the minimum and maximum wheat commercialization index was 0.1 (subsistence) and 0.95 (commercialized) with mean and standard deviations of 0.43 and 0.21 , respectively. Additionally, the mean wheat commercialization index of subsistence, semicommercialized, and commercialized smallholder farmers were $0.21,0.38$, and 0.73 , respectively. Moreover, the report of this study indicated that $23.4 \%$, $51.9 \%$, and $24.7 \%$ of smallholder farmers were subsistence, semicommercialized, and commercialized, respectively (Table 3). Therefore, the majority of the smallholder farmers fall in the semicommercialized category. For example, Bekele et al. [47] and Mamo et al. [33] conducted a study on teff and wheat commercialization in Ethiopia, respectively. Their findings indicated that most of the respondents fall in the semicommercialized category. Therefore, the result of this study is consistent with previous studies.

Further analysis of the data indicated that 59\% of smallholder farmers' wheat commercialization index was less than the mean commercialization index, whereas $41 \%$ of the respondents' wheat commercialization index was higher than the mean of the total observation. This indicates that the commercialization index of smallholder wheat producers was skewed to a semicommercialized production system. Likewise, the result of this study was compared with previous wheat, sorghum, teff, coffee, ginger, and turmeric commercialization studies conducted in Ethiopia $[33,46,47]$. Finally, the result of this study is higher than previous wheat $(0.27)$ and sorghum (0.35) commercialization indices but lower than teff $(0.46)$, coffee $(0.8)$, ginger (0.83), and turmeric (0.85) commercialization indices. This is because teff, coffee, ginger, and turmeric are major cash crops as compared to wheat. On the other hand, sorghum is 
Table 2: Definition, measurement, and expected signs of hypothesized variables.

\begin{tabular}{|c|c|c|c|}
\hline Variable name & Definition of variables & Measurement & Expected sign \\
\hline SEXOFHH & Sex of household head & 1 if male-headed, 0 otherwise & + \\
\hline EDUSTATUS & Educational status & 1 if literate, 0 otherwise & + \\
\hline DEPNDRATIO & Dependency ratio & Ratio & - \\
\hline ANNINCOME & Annual income & Ethiopian birr & + \\
\hline OXENOWN & Number of oxen owned & Number & + \\
\hline LANDSIZE & Land size (wheat) & Hectare & + \\
\hline FARMEXPE & Farming experience (wheat) & Year & + \\
\hline EXTENSERV & Extension service & 1 if user, 0 otherwise & + \\
\hline CREDITSUT & Credit service utilization & 1 if user, 0 otherwise & + \\
\hline MISTARKETD & Market distance & Walking minute & - \\
\hline
\end{tabular}

TABLE 3: Summary statistics of level of wheat commercialization.

\begin{tabular}{|c|c|c|c|c|c|}
\hline \multirow{2}{*}{ Level of commercialization } & \multicolumn{4}{|c|}{ Wheat commercialization index } & \multirow{2}{*}{ Number (\%) } \\
\hline & Minimum & Maximum & Mean & Standard deviation & \\
\hline Subsistence & 0.1 & 0.25 & 0.21 & 0.04 & $36(23.4)$ \\
\hline Semicommercialized & 0.28 & 0.50 & 0.38 & 0.07 & $80(51.9)$ \\
\hline Commercialized & 0.53 & 0.95 & 0.73 & 0.11 & $38(24.7)$ \\
\hline Total sample & 0.1 & 0.95 & 0.43 & 0.21 & $154(100)$ \\
\hline
\end{tabular}

Source: own survey (2018).

produced to meet the food consumption needs of household members, and the market demand of sorghum is not attractive as compared to wheat. Similarly, the wheat commercialization index of previous studies $(0.27)$ is less than the mean wheat commercialization index of this study (0.43). This implies that the smallholder farmers' participation in the output market is better than other area smallholder farmers.

On average, 29.48, 34.43, and 70.73 quintal (1 quin$\mathrm{tal}=100 \mathrm{~kg}$ ) wheat per hectare were produced by subsistence, semicommercialized, and commercialized smallholder farmers, respectively. Wheat production in Debre Elias Woreda is dual purpose (food and cash crop). So, the average amount of wheat consumed by subsistence, semicommercialized, and commercialized smallholder farmers was 22.76, 19.83, and 24.18 quintal per hectare, respectively. On the other hand, the amount of wheat sold varies from farmer to farmer. The average quantity of wheat sold by commercialized farmers (46.55 quintals) was greater than that by semicommercialized (14.60 quintals) and subsistence smallholder farmers (6.72 quintal). When we see the value of total wheat produced and the wheat sale in the market, commercialized farmers take the lions' share followed by semicommercialized and subsistence smallholder farmers (Table 4 ). The $F$-test result revealed that the mean difference among levels of wheat commercialization and the amount of wheat produced, the quantity of wheat sold, the value of total wheat produced, and the value of wheat sale were statistically significant at $p<0.01$ significance level.

3.2. Relationship between Categorical Variables and the Level of Commercialization. The survey result indicated that about $66.9 \%$ of smallholder farmers were male-headed households, whereas $33.1 \%$ were female-headed households. The crosstabulation result revealed that $16.2 \%, 39 \%$, and $11.7 \%$ male- headed households were subsistence, semicommercialized, and commercialized wheat producers, respectively. On the other hand, $16.2 \%, 14.3 \%$, and $2.6 \%$ of female-headed households were subsistence, semicommercialized, and commercialized wheat producers, respectively. The chisquare test result revealed that the sex of the household head and level of wheat commercialization had a statistically significant association at $p<0.01$ significance level (Table 5). From this, we can conclude that the majority of male-headed and female-headed households were semicommercialized and subsistence wheat producers, respectively. Moreover, the survey result indicated that $68.2 \%$ and $31.8 \%$ of the respondents were literate and illiterate, respectively. As depicted in Table $4,13.8 \%, 44.2 \%$, and $11 \%$ of literate households were subsistence, semicommercialized, and commercialized smallholder farmers, respectively. The chisquare test result revealed that educational status and level of wheat commercialization had a statistically significant association at $p<0.01$ significance level. This implies that the majority of the literate smallholder farmers were categorized under semicommercialized category unlike illiterate smallholder farmers (subsistence category).

Extension agents bring best practices from other Woredas, zones, and regions and provide supportive services to improve production potentials of smallholder farmers. Therefore, to capture this variable, extension service was incorporated in the analysis. The result indicated that $28.6 \%$ of extension service users and $25.3 \%$ of extension service nonusers were semicommercialized and subsistence wheat producers, respectively. The association between extension service and level of wheat commercialization was statistically significant at $p<0.01$ significance level. Besides extension service, credit service is one way of improving smallholder farmers' production and productivity. Smallholder farmers' ability to purchase inputs such as improved seeds, fertilizer, 
TABLE 4: Amount of wheat produced, consumed, and sold in quintal.

\begin{tabular}{lccc}
\hline Wheat production & Level of wheat commercialization & Commercialized \\
& Semicommercialized & 34.43 & 70.73 \\
\hline Amount of wheat produced & 29.48 & 19.83 & 24.18 \\
Amount of wheat consumed & 22.76 & 14.60 & 46.55 \\
Total quantity sold & 6.72 & 27119.68 & 37186.82 \\
Value of wheat produced & 23187.88 & 10414.28 & $28.618^{* * *}$ \\
Value of wheat sale & 4615.06 & & 28237.78 \\
\hline
\end{tabular}

Source: own survey (2018).

TABLE 5: Summary statistics of categorical variables and level of commercialization.

\begin{tabular}{|c|c|c|c|c|c|c|}
\hline \multirow[b]{2}{*}{ Variables } & \multirow[b]{2}{*}{ Categories } & \multicolumn{5}{|c|}{ Level of wheat commercialization } \\
\hline & & $\begin{array}{c}\text { Subsistence } \\
\text { Number (\%) }\end{array}$ & $\begin{array}{c}\text { Semicommercialized } \\
\text { Number }(\%)\end{array}$ & $\begin{array}{l}\text { Commercialized } \\
\text { Number (\%) }\end{array}$ & Total samples & Chi-square test \\
\hline \multirow{2}{*}{ Sex of household head } & Male & $25(16.2)$ & $60(39)$ & $18(11.7)$ & $103(66.9)$ & \multirow{2}{*}{$10.11^{* * *}$} \\
\hline & Female & $25(16.2)$ & $22(14.3)$ & $4(2.6)$ & $51(33.1)$ & \\
\hline \multirow{2}{*}{ Educational status } & Literate & $20(13)$ & $68(44.2)$ & $17(11)$ & $105(68.2)$ & \multirow{2}{*}{$27.36^{* * *}$} \\
\hline & Illiterate & $30(19.5)$ & $14(9.1)$ & $5(3.2)$ & $49(31.9)$ & \\
\hline \multirow{2}{*}{ Extension service } & User & $11(7.1)$ & $44(28.6)$ & $12(7.8)$ & $67(43.5)$ & \multirow{2}{*}{$13.94^{* * *}$} \\
\hline & Nonuser & $39(25.3)$ & $38(24.7)$ & $10(6.5)$ & $87(56.5)$ & \\
\hline \multirow{2}{*}{ Credit service } & User & $18(11.7)$ & $28(18.2)$ & $5(3.2)$ & $51(33.1)$ & \multirow{2}{*}{1.29} \\
\hline & Nonuser & $32(20.8)$ & $54(35.1)$ & $17(11)$ & $103(66.9)$ & \\
\hline
\end{tabular}

Source: own survey (2018).

herbicides, and pesticides tied with credit service. Farmers using credit service can minimize their financial constraints and buy inputs more readily than nonusers of credit services. Thus, access to credit service increases the production of crops in general wheat production in particular, but the survey result indicated that the majority of credit users and nonusers were semicommercialized farmers which implies that credit service had no significant association with the level of wheat commercialization.

3.3. Relationship between Continuous Variables and the Level of Commercialization. The result of this study revealed that the average dependency ratio for subsistence, semicommercialized, and commercialized smallholder farmers was $0.63,0.53$, and 0.31 , respectively. This implies that the dependency ratio of subsistence smallholder farmers is higher than that of semicommercialized and commercialized smallholder farmers. This mean difference was statistically significant at $p<0.01$ significance level (Table 6). On the contrary, the average numbers of oxen for commercialized smallholder farmers (5.45) were higher than that of semicommercialized (2.91) and subsistence (2.74) smallholder farmers. $F$-test was employed to evaluate the mean oxen difference among the level of wheat commercialization. The result indicated that the mean difference was statistically significant at $p<0.01$ significance level.

Similarly, the average income of subsistence, semicommercialized, and commercialized smallholder farmers was 9378.70, 17865.61, and 24163.04 Ethiopian birr (ETB), respectively. This mean difference was statistically significant at $p<0.01$ significance level. Correspondingly, the average land size allocated to wheat production of commercialized farmers was $2.91 \mathrm{ha}$, which was higher than the average land size of semicommercialized (1.07 ha) and subsistence smallholder farmers $(0.91 \mathrm{ha})$. The mean difference was statistically significant at $p<0.01$ significance level. This implies that land size allocated to wheat production increases the smallholder farmers' wheat commercialization. Likewise, the average farming experience of smallholder farmers in wheat production of commercialized farmers (34.5 years) was more than semicommercialized (19.7 years) and subsistence (17.9 years) smallholder farmers. This indicated that having more experience in wheat production increases the wheat commercialization level of smallholder farmers. The F-test result indicated that the mean farm experience difference among wheat commercialization levels was statistically significant at $p<0.01$ significance level.

Moreover, market distance is the most important variable to determine smallholder farmers' participation in the market to sell their produce. The presence of surplus agricultural production is not an end to improve the living standard of smallholder farmers. The issue of infrastructure particularly market access serves as a backbone to transport production from a surplus area to deficit areas. In light of this explanation, distance from the nearest market was incorporated as an independent variable, and its relationship with the level of wheat commercialization was measured. Based on the survey result, the average distance from the nearest market for subsistence, semicommercialized, and commercialized smallholder farmers was $152.80,147.56$, and 94.55 minutes, respectively. The mean difference was statistically significant at $p<0.01$ significance level. 
TABLE 6: Summary statistics of continuous variables (mean) and level of commercialization.

\begin{tabular}{lcccc}
\hline Variables & & Level of wheat commercialization & \\
& Subsistence & Semicommercialized & Commercialized & 0.31 \\
\hline Dependency ratio & 0.63 & 0.53 & 5.45 & $7.09^{* * *}$ \\
Number of oxen & 2.74 & 2.91 & 45976.4 & $31.34^{* * *}$ \\
Annual income & 9378.7 & 17865.6 & 2.91 & $26.98^{* * *}$ \\
Land size & 0.91 & 1.07 & 34.5 & $14.46^{* * *}$ \\
Farming experience & 17.86 & 19.79 & 94.55 & $7.84^{* * *}$ \\
Market distance & 152.8 & 147.56 & $59.59^{* * *}$ \\
\hline
\end{tabular}

Source: own survey (2018).

3.4. Econometric Model Result. The beta regression model was applied to analyze the determinants of the wheat commercialization index score. For this purpose, ten explanatory variables were incorporated into the model to analyze the factors affecting wheat commercialization. The model result indicated that smallholder farmers' wheat commercialization is influenced by several socioeconomic and institutional factors. The chi-square value indicated that the parameters included in the model taken together are significantly different from zero at $p<0.01$ significance level. Table 7 presents the sign, magnitude, statistical tests, and significance level of each explanatory variable. Among the variables, educational status, number of oxen, land size allocated to wheat production, farming experience in wheat production, extension service, and market distance had a statistically significant effect on wheat commercialization at $p<0.01$ significance level. On the other hand, annual income had a statistically significant effect on wheat commercialization at $p<0.1$ significance level (Table 7).

\section{Discussion}

In the study area, wheat commercialization was influenced by socioeconomic and institutional factors. For example, the estimated coefficient of educational status shows a positive effect on wheat commercialization. The marginal effect result indicates that wheat commercialization will be increased by $4.33 \%$ if the household head is literate. This entails that an increase in the number of literate household heads increases the amount of wheat production and volume of wheat marketed surplus because educated household heads adopt best practices to increase their production and productivity which in turn increases the volume they will supply to the market. Additionally, literate household heads have better awareness about the benefits of using improved agricultural technologies to increase wheat production and productivity besides the opportunity cost of using backward agricultural practices than illiterate household heads. Furthermore, education enables the household heads to understand market dynamics in terms of demand, supply, and market prices to make the appropriate decision about the volume of wheat supplied to the market. Bekele et al. [47], Mohammed et al. [46], and Tufa et al. [63], who conducted studies on teff, wheat, and horticultural crops commercialization in Ethiopia, found a positive and significant effect of educational status on commercialization.

The annual income of the previous year is another variable that had a statistically significant and positive effect on wheat commercialization. This entails that the households who have higher annual income have higher wheat commercialization than their counterparts. The marginal effect result of the model indicates that a unit increase in annual income of the households will result in a $2.4 \%$ increase in wheat commercialization. In Ethiopia, particularly in Debre Elias Woreda, smallholder farmers are constrained by chronic cash shortage to purchase improved agricultural inputs for wheat production. From this, we can conclude that having more cash income increases the smallholder farmers' agricultural input purchasing power. This finding is consistent with previous similar studies [37, 44].

Similarly, several oxen owned by the households had a significant and positive effect on wheat commercialization at $p<0.01$ significance level. As the number of oxen owned by the households' increases, the smallholder farmers' extent of wheat commercialization would be increased. In Ethiopia, particularly in the study area, an ox is the major source of traction power. Wheat production requires at least three tillage frequencies to get better produce. Therefore, households who have more number of oxen could meet the standard tillage frequency of wheat production than their counterparts. Additionally, more number of oxen owners provide oxen hire service for others. This indicates that having more oxen increases the financial capacity of smallholder farmers to purchase the best agricultural practices. As the model result indicated, increasing the number of oxen by one unit will increase wheat commercialization by $4.33 \%$. This finding is in line with previous studies [45].

The model result confirms that the size of the land allocated to wheat production and wheat commercialization had a positive relationship. The marginal effect result indicates that a one-hectare increase in the size of the land allocated to wheat production would increase wheat commercialization by $16.88 \%$. This illustrates that the larger the land size allocated to wheat production, the higher would be the output which increases the volume of wheat supplied to the market. This indicates that land size is an important variable to determine smallholder farmers' participation in commercial farming. This result is consistent with previous studies [8, 36, 64]. Likewise, the coefficient of farm experience in wheat production had a positive and significant relationship with wheat commercialization. This shows that experienced farmers have more knowledge about wheat farming, weather forecasting ability, market force dynamics, use of improved wheat technologies, and good network with 
TABLe 7: Parameter estimates of the beta regression model.

\begin{tabular}{|c|c|c|c|c|c|}
\hline Variables & Coef. & Std. err. & $z$-value & $p>z$ & Marginal effect \\
\hline Sex of household head & -0.0219 & 0.0749 & -0.2900 & 0.7700 & -0.0046 \\
\hline Educational status & $0.2054^{* * *}$ & 0.0798 & 2.5700 & 0.0100 & 0.0433 \\
\hline Dependency ratio & -0.1238 & 0.1087 & -1.1400 & 0.2550 & -0.0261 \\
\hline Annual income & $0.1137^{*}$ & 0.0591 & 1.9200 & 0.0540 & 0.0240 \\
\hline Number of oxen owned & $0.2053^{* * *}$ & 0.0729 & 2.8200 & 0.0050 & 0.0433 \\
\hline Land size (wheat) & $0.8003^{* * *}$ & 0.0980 & 8.1700 & 0.0000 & 0.1688 \\
\hline Farming experience (wheat) & $0.3944^{* * *}$ & 0.0803 & 4.9100 & 0.0000 & 0.0832 \\
\hline Extension service & $0.2805^{* * *}$ & 0.0693 & 4.0500 & 0.0000 & 0.0592 \\
\hline Credit service utilization & 0.0532 & 0.0731 & 0.7300 & 0.4660 & 0.0112 \\
\hline Market distance & $-0.4755^{* * *}$ & 0.0865 & -5.5000 & 0.0000 & -0.1003 \\
\hline Constant & -0.2269 & 0.7410 & -0.3100 & 0.7590 & \\
\hline LR chi $^{2}(10)$ & & & & & $245.44^{* * *}$ \\
\hline Log-likelihood & & & & & 157.07 \\
\hline Observations & & & & & 154 \\
\hline
\end{tabular}

Source: own survey (2018); ${ }^{*}$ and ${ }^{* * *}$ significant at $p<0.01$ and 0.1 , respectively.

market actors which increases wheat production, productivity, and quantity supplied to the market. The marginal effect result revealed that a year increase in farm experience in wheat production will result in an $8.32 \%$ increase in wheat commercialization. This result is consistent with previous studies $[8,37,64]$.

As it was hypothesized, extension service had a positive relationship with wheat commercialization. This implies that extension service users could adopt improved wheat technologies and have the better technical skill to manipulate improved wheat technologies and the opportunity cost of using obsolete agricultural technologies. In addition to this, extension service providers give training for farm households about commercial farming and its advantages that would increase their market participation. Therefore, extension service is a bridge between farm households' technology and management gaps and technology innovators. The marginal effect result indicates that being an extension service user will increase wheat commercialization by $5.92 \%$. Conversely, market distance had a negative and significant effect on wheat commercialization. The model result revealed that an increase in market distance will decrease wheat commercialization by $10.03 \%$. This indicates that smallholder farmers who live near to the market are more likely to have a higher level of wheat commercialization than those who are further away from the market. The closer the smallholder farmers are to the output market, the higher the wheat commercialization level due to better information access on the dynamics of market forces and reduced transportation costs. The findings by Hailua et al. [36], Mazengia [8], and Tufa et al. [63] indicated that market distance and commercialization level had a negative and significant effect on commercialization, consistent with the result of this study.

\section{Conclusion}

Motivated by the gaps of previous studies and wheat potential of Debre Elias Woreda, this study was undertaken to measure the level of wheat commercialization and examine factors that hamper wheat commercialization using the output commercialization index and the beta regression model, respectively. The result indicated that the majority of smallholder farmers are semicommercial wheat producers. In general, smallholder farmers in the study area have a huge potential in wheat commercialization as compared to other wheat-producing areas. Therefore, smallholder wheat producer farmers should be encouraged to efficiently participate in the wheat output market to improve their living standards. Additionally, intervention strategies that increase wheat productivity should also be implemented to enable smallholder farmers to produce a marketable surplus to satisfy input demands of macaroni, spaghetti, wheat powder, and bakery factories which have been established in and around Debre Elias.

Moreover, the econometric model result indicated that educational status, annual income, number of oxen, land size allocated to wheat production, farming experience in wheat production, extension service, and market distance had a statistically significant effect on wheat commercialization. The findings of this study indicate that an attempt to increase smallholder farmers' participation in the output market should give special attention to significant explanatory variables. Especially, an increase in oxen ownership increases the commercialization of smallholder wheat producer farmers. Hence, special priority should be given to mechanized farming to scale up the production capacity of smallholder farmers which leads to a high degree of wheat commercialization. The annual income of the previous year positively influenced smallholder farmers' wheat commercialization. This indicates that income is an important variable that affects the participation of farm households in the input and output markets. Consequently, policymakers and smallholder farmers should design strategies to diversify their income sources to strengthen their financial capacity. Additionally, land size allocated to wheat production had a positive effect on wheat commercialization. As a result, land productivity-enhancing technologies should be designed and implemented. Besides this, land resources are limited in the study area. Therefore, output-output production-based education, training, and extension service should be executed to increase land productivity to surge smallholder farmers' participation in the output market. 
Moreover, the distance from the nearest market negatively affects smallholder farmers' wheat commercialization. Therefore, wheat commercialization should be improved by investing in necessary facilities like market access, market infrastructure, road, and transportation service.

\section{Data Availability}

The data used to support the findings of this study are available from the corresponding author upon request.

\section{Conflicts of Interest}

The authors declare that there are no conflicts of interest regarding the publication of this paper.

\section{Acknowledgments}

This study was supported by Debre Markos University, Bahir Dar University, and the Ethiopian Ministry of Education.

\section{References}

[1] J. Abafita, J. Atkinson, and C. Kim, "Smallholder commercialization in Ethiopia: market orientation and participation," International Food Research Journal, vol. 2, no. 1, 2016.

[2] B. F. Johnston and J. W. Mellor, "The role of agriculture in economic development," The American Economic Review, vol. 514, pp. 566-593, 1961.

[3] C. Carletto, P. Corral, and A. Guelfi, "Agricultural commercialization and nutrition revisited: empirical evidence from three African countries," Food Policy, vol. 67, pp. 106$118,2017$.

[4] S. O. Ogutu and M. Qaim, "Commercialization of the small farm sector and multidimensional poverty," World Development, vol. 114, pp. 281-293, 2019.

[5] P. Tipraqsa and P. Schreinemachers, "Agricultural commercialization of Karen Hill tribes in northern Thailand," Agricultural Economics, vol. 40, no. 1, pp. 43-53, 2009.

[6] F. Rabbi, R. Ahamad, S. Ali et al., "Determinants of commercialization and its impact on the welfare of smallholder rice farmers by using Heckman's two-stage approach," Journal of the Saudi Society of Agricultural Sciences, vol. 18, no. 2, pp. 224-233, 2019.

[7] A. S. Taffes, P. Dorosh, and S. A. Gemessa, "Crop production in Ethiopia: regional patterns and trends," in Food and Agriculture in Ethiopia: Progress and Policy Challenges, University of Pennsylvania Press, Philadelphia, PA, USA, 2012.

[8] Y. Mazengia, "Smallholders commercialization of maize production in Guangua district, northwestern Ethiopia," World Scientific News, vol. 58, pp. 65-83, 2016.

[9] P. L. Pingali, "From subsistence to commercial production systems: the transformation of Asian agriculture," American Journal of Agricultural Economics, vol. 79, no. 2, pp. 628-634, 1997.

[10] P. Arias, D. Hallam, E. Krivonos, and J. Morrison, Smallholder Integration in Changing Food Markets, Food and Agriculture Organization of the United Nations, Rome, Italy, 2013.

[11] P. L. Pingali and M. W. Rosegrant, "Agricultural commercialization and diversification: processes and policies," Food Policy, vol. 20, no. 3, pp. 171-185, 1995.
[12] B. Gebremedhin, D. Hoekstra, and A. Tegegne, "Commercialization of Ethiopian agriculture: extension service from input supplier to knowledge broker and facilitator," 2006.

[13] S. Gebreselassie and K. Sharp, "Commercialisation of smallholder agriculture in selected Tef-growing areas of Ethiopia," Ethiopian Journal of Economics, vol. 16, no. 1, pp. 55-86, 2007.

[14] C. P. Timmer, "Farmers and markets: the political economy of new paradigms," American Journal of Agricultural Economics, vol. 79, no. 2, pp. 621-627, 1997.

[15] I. Mohammed Nasir, W. Mulugeta, and B. Kassa, "Impact of commercialization on rural households' food security in major coffee growing areas of South West Ethiopia: the case of Jimma Zone," International Journal of Economics \& Management Sciences, vol. 6, no. 4, 2014.

[16] NBE, National Bank of Ethiopia (NBE), Annual Report 2016/ 17; Addis Ababa, National Bank of Ethiopia, Addis Ababa, Ethiopia, 2017.

[17] CSA, "The federal democratic republic of Ethiopia central statistical agency agricultural sample survey," Report on area and production of major crops, CSA, Longueuil, Canada, 2018.

[18] CSA, "Large and medium scale commercial farms sample survey," CSA, Longueuil, Canada, Results at country and regional level, 2015.

[19] CSA, "Agricultural sample survey 2015/2016 (2008 E.C)," Report on area and production of major crops, CSA, Longueuil, Canada, 2016.

[20] L. Dube and E. Guveya, "Determinants of agriculture commercialization among smallholder farmers in Manicaland and Masvingo Provinces of Zimbabwe," Agricultural Science Research Journal, vol. 68, pp. 182-190, 2016.

[21] A. Workineh, Y. Nega, and D. Habte, "Planting density, and nitrogen and phosphorus fertilization effect on different bread wheat (Triticum aestivum L.) genotypes in Southern Tigray, Ethiopia," World Journal of Medicine and Medical Science Research, vol. 32, pp. 020-028, 2015.

[22] ATA, Agricultural Transformation Agency, 2014.

[23] CSA, "Agricultural sample survey report on area and production of major crops," in Statistical Bulletin (532), Vol. 6, CSA, Addis Ababa, Ethiopia, 2014.

[24] A. Tidiane, T. Chiari, W. Legesse et al., "Durum wheat (Triticum durum desf.): origin, cultivation and potential expansion in sub-saharan Africa," Agronomy, vol. 9, no. 5, p. 263, 2019.

[25] A. William, B. Alain, and V. G. Maarten, The World Wheat Book: A History of Wheat Breeding, Lavoisier, Paris, France, 2011.

[26] B. Juarez and D. Wolf, "Grain and feed annual Mexico," in Global Agricultural Information, pp. 1-17, USDA Foreign Agricultural Service, Washington, DC, USA, 2015.

[27] S. El-Areed, M. M. Nachit, A. Hagaras et al., "Durum wheat breeding for high yield potential in Egypt," in Proceedings of the International Symposium on Genetics and Breeding of Durum Wheat, E. Porceddu, A. B. Damania, and C. O. Qualset, Eds., pp. 291-294, CIHEAM, Bari, Italy, 2013.

[28] K. Bergh, A. Chew, M. K. Gugerty, and C. L. Anderson, "Wheat value chain: Ethiopia," Gates Open Research, vol. 3, 2019.

[29] A. Aleminew, G. Alemayehu, E. Adgo, and V. Herrero, "Response of noug (Guizotia abyssinica Cass.) to Np fertilizers application and seeding rates on yield and yield components in Ebinat District, Amhara Region, Ethiopia," World Journal of Agricultural Sciences, vol. 1170-83, 2015. 
[30] A. Goitom, "Commercialization of smallholder farming: determinants and welfare outcomes, a cross-sectional study in Enderta district, Tigrai, Ethiopia," 2009.

[31] A. Berhanu, "Economic effects of cash crops production on farmers welfare: giving farmers a better deal in Oromia," 2012.

[32] A. Mitiku, "Impact of smallholder farmers agricultural commercialization on rural households' poverty," The International Journal of Applied Economics and Finance, vol. 8, no. 2, pp. 51-61, 2014.

[33] T. Mamo, W. Getahun, A. Tesfaye et al., "Analysis of wheat commercialization in Ethiopia: the case of SARD-SC wheat project innovation platform sites," African Journal of Agricultural Research, vol. 12, no. 10, pp. 841-849, 2017.

[34] A. Falola, B. Achem, W. Oloyede, and G. Olawuyi, "Determinants of commercial production of wheat in Nigeria: a case study of Bakura local government area, Zamfara state," Trakia Journal of Sciences, vol. 15, no. 4, pp. 397-404, 2017.

[35] A. G. Gari, "Determinants of smallholders wheat commercialization: the case of Gololcha district of Bale zone, Ethiopia," 2017.

[36] G. Hailua, K. Manjureb, and K.-M. Aymutc, "Crop commercialization and smallholder farmers livelihood in Tigray region, Ethiopia," Journal of Development and Agricultural Economics, vol. 79, pp. 314-322, 2015.

[37] H. M. Kabiti, N. E. Raidimi, T. K. Pfumayaramba, and P. K. Chauke1, "Determinants of agricultural commercialization among smallholder farmers in Munyati resettlement area, Chikomba district, Zimbabwe," Journal of Human Ecology, vol. 53, no. 1, pp. 10-19, 2016.

[38] S. Ferrari and F. Cribari-Neto, "Beta regression for modelling rates and proportions," Journal of Applied Statistics, vol. 31, no. 7, pp. 799-815, 2004.

[39] C. F. Baum, "Stata tip 63: modeling proportions," The Stata Journal: Promoting Communications on Statistics and Stata, vol. 8, no. 2, pp. 299-303, 2008.

[40] S. Gallani, R. Krishnan, and J. M. Wooldridge, "Applications of fractional response model to the study of bounded dependent variables in accounting research," SSRN Electronic Journal, 2015.

[41] B. H. Kotu, H. Verkuijl, W. Mwangi, and D. Tanner, "Adoption of improved wheat technologies in Adaba and Dodola Woredas of the Bale Highlands, Ethiopia," 2000.

[42] A. Melaku and A. Abebe, "Bovine trypanosomosis and its vector type and density at Debre Elias district, north-western, Ethiopia," Journal of Advanced Veterinary Research, vol. 24, pp. 247-251, 2012.

[43] J. Govereh, T. Jayne, and J. Nyoro, Smallholder Commercialization, Interlinked Markets and Food Crop Productivity: Cross-Country Evidence in Eastern and Southern Africa, Vol. 39, Michigan State University, Department of Agricultural Economics and Department of Economics, East Lansing, MI, USA, 1999.

[44] A. B. Musah, Y. B. Osei-Asare, and W. Seini, "Market participation of smallholder maize farmers in the upper west region of Ghana," African Journal of Agricultural Research, vol. 9, no. 31, pp. 2427-2435, 2014.

[45] T. Leta Edosa, "Determinants of commercialization of teff crop in abay Chomen district, Horo Guduru Wallaga zone, Oromia regional state, Ethiopia," Journal of Agricultural Extension and Rural Evelopment, vol. 10, no. 12, pp. 251-259, 2018.

[46] A. Mohammed, M. Baze, and M. Ahmed, "Smallholder commercialization and commercial farming in coffee-spice based farming system of South West Ethiopia," International
Journal of Research Studies in Agricultural Sciences, vol. 2, no. 5, pp. 13-26, 2016.

[47] A. Bekele, A. G. Tefera, and D. Goshu, "Determinants of commercialization and market outlet choices of Tef: the case of smallholder farmers in Dendi district of Oromia, Central Ethiopia," 2018.

[48] M. Hunger, J. Baumert, and R. Holle, "Analysis of SF-6D index data: is beta regression appropriate?" Value in Health, vol. 14, no. 5, pp. 759-767, 2011.

[49] E. M. Pullenayegum, J.-E. Tarride, F. Xie, R. Goeree, H. C. Gerstein, and D. O'reilly, "Analysis of health utility data when some subjects attain the upper bound of 1: are tobit and CLAD models appropriate?" Value in Health, vol. 13, no. 4, pp. 487-494, 2010.

[50] S. Ferrari, "Beta regression modeling: recent advances in theory and applications, 13th school of regression models," 2013.

[51] J. M. Wooldridge, Correlated Random Effects Models with Unbalanced Panels, Michigan State University, Department of Economics, East Lansing, MI, USA, 2010.

[52] L. E. Papke and J. M. Wooldridge, "Panel data methods for fractional response variables with an application to test pass rates," Journal of Econometrics, vol. 145, no. 1-2, pp. 121-133, 2008.

[53] S. Aktaş and H. Unlu, "Beta regression for the indicator values of well-being index for provinces in Turkey," Journal of Engineering Technology and Applied Sciences, vol. 2, no. 2, pp. 101-111, 2017.

[54] M. Hunger, A. Döring, and R. Holle, "Longitudinal beta regression models for analyzing health-related quality of life scores over time," BMC Medical Research Methodology, vol. 12, no. 1, p. 144, 2012.

[55] D. O. Cook, R. Kieschnick, and B. D. Mccullough, "Regression analysis of proportions in finance with self selection," Journal of Empirical Finance, vol. 15, no. 5, pp. 860-867, 2008.

[56] R. Kieschnick and B. D. Mccullough, "Regression analysis of variates observed on $(0,1)$ : percentages, proportions and fractions," Statistical Modelling: An International Journal, vol. 3, no. 3, pp. 193-213, 2003.

[57] A. G. Osmani and E. Hossain, "Market participation decision of smallholder farmers and its determinants in Bangladesh," Economics of Agriculture, vol. 62, no. 1, pp. 163-179, 2015.

[58] J. Von Braun, "Agricultural commercialization: impacts on income and nutrition and implications for policy," Food Policy, vol. 20, no. 3, pp. 187-202, 1995.

[59] L. Latruffe and Y. Desjeux, "Perpetuation of subsistence farming in Kosovo: the role of farm integration in input markets," Post-communist Economies, vol. 26, no. 1, pp. 137-148, 2014.

[60] S. Kimei, P. Mshenga, and E. Birachi, "Factors influencing commercialization of beans among smallholder farmers in Rwanda," IOSR Journal of Agriculture and Veterinary Science, vol. 10, no. 8, pp. 30-34, 2017.

[61] A. Bekele and D. Alemu, "Farm-level determinants of output commercialization: in haricot bean based farming systems," Ethiopian Journal of Agricultural Sciences, vol. 251, pp. 61-69, 2015.

[62] J. L. Pender and D. Alemu, "Determinants of smallholder commercialization of food crops: theory and evidence from Ethiopia," 2007.

[63] A. Tufa, A. Bekele, and L. Zemedu, "Determinants of smallholder commercialization of horticultural crops in gemechis district, west hararghe zone, Ethiopia," African Journal of Agricultural Research, vol. 9, no. 3, pp. 310-319, 2014. 
[64] J. Haji, A. Negesse, and B. Tegegne, "Determinants of smallholder farmers' commercialization of potato and head cabbage in Kofale district, West Arsi zone, Oromia regional state, Ethiopia," 2018. 